\title{
DEVELOPMENT OF THE METHOD OF CONDUCTING ANESTHESIA OF ZYGOMATICOFACIAL NERVE IN PEOPLE WITH DIFFERENT FACE SHAPE AND ITS CLINICAL EVALUATION
}

\author{
Oleg Mokryk', Jakub Hadzik², Volodymyr Shybinskyy ${ }^{3}$ \\ 'Department of Surgical Dentistry and Maxillofacial Surgery, Danylo Halytsky Lviv National Medical University, Lviv, Ukraine \\ ${ }^{2}$ Department of Dental Surgery, Medical University of Wroclaw, Wroclaw, Poland \\ ${ }^{3}$ Department of Prosthetic Dentistry, Danylo Halytsky Lviv National Medical University, Lviv, Ukraine
}

\begin{abstract}
INTRODUCTION: The branching of the trigeminal nerve on the face has an individual anatomical variability. The individual variability of innervation of the maxillofacial area should be taken into account during local anesthesia.

ОвјеCтIVEs: The purpose of the study was to develop a method of conducting anesthesia of the zygomaticofacial nerve.

MATERIAL AND METHODS: Craniometric examinations were performed on 32 natural skulls of corpses of various ages, and 60 images of patients' head section were completed in a 3D reconstruction by multi-detector row spiral computed tomography. The cranial index was determined by counting the number of zygomaticofacial foramina on each skull, taking into account the peculiarities of their location. Sixty-one surgical dental patients with planned surgical interventions on the lateral facial area beforehand participated in this clinical observation. A developed technique of conductive anesthesia of the zygomaticofacial nerve was applied in thirty patients, and its effectiveness was compared with a known method.

RESULTS: A certain feature in the localization of zygomaticofacial foramina on the lateral (facial) surface of zygomatic bone, depending on the type of structure of the skull was discovered.

ConcLusions: Taking into account the results of craniometric studies as well as the individual topographic and anatomical features of zygomaticofacial nerve branching in people with different types of skull structure, the technique of performing anesthesia of the branches of zygomaticofacial nerve was developed. In order to anesthetize this nerve in people with broad and oblong face shape, anatomical variability of its branching should be considered.
\end{abstract}

KEY wORDs: anesthesia, dental, local anesthesia, craniometry, zygomatic anesthesia.

J Stoma 2019; 72, 6: 245-251

DOI: https://doi.org/10.5114/jos.2019.93843

\section{INTRODUCTION}

It is well known that the sensory innervation of the maxillofacial area (MFA) is quite complicated. In the soft tissues of the face, the sensory branches of the trigeminal nerve as well as the cervical superficial nerve plexus are branching (Figure 1) $[1,2]$. In adjacent anatomical sites, these nerves anastomose with each other. The branching of the trigeminal nerve on the face has an individual anatomical variability, dividing into two types [3]

\section{JOURNAL OF STOMATOLOGY CZASOPISMO STOMATOLOGICZNE

ADDRESS FOR CORRESPONDENCE: Dr. Jakub Hadzik, Dental Surgery Department, Medical University of Wroclaw, 26 Krakowska Str., 50-425 Wrocław, Poland, e-mail: jakub.hadzik@umed.wroc.pl

ReCEIVED: 31.12.2019 • ACCEPTED: 02.02.2020 • PUBLISHED: 10.03.2020 

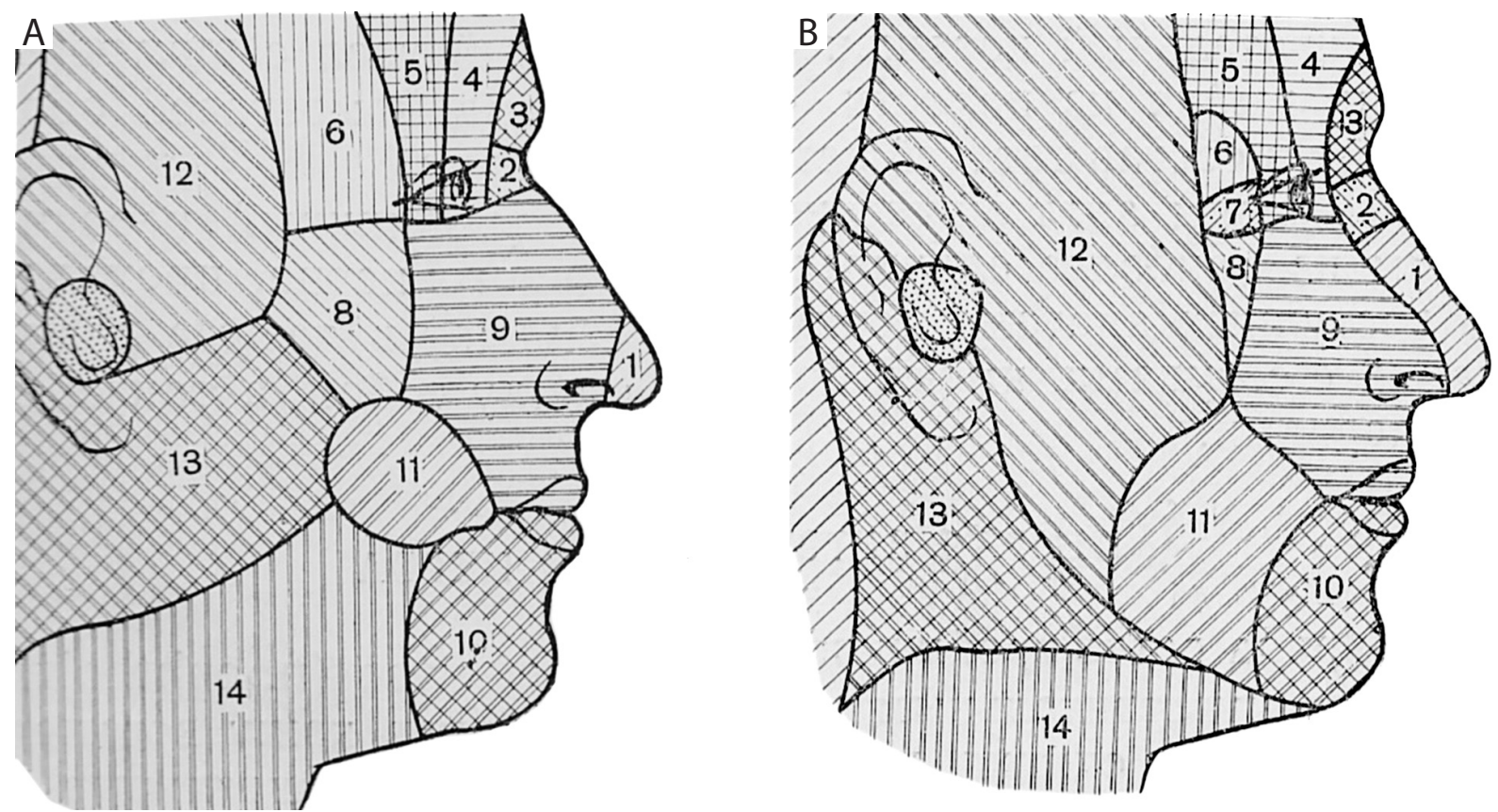

FIGURE 1. Types of branching on the face of the superficial branches of trigeminal nerve and cervical nerve plexus (according to VN Shevkunenko): A) with dominating of the superficial branches of the maxillary nerve and cervical nerve plexus on the face, $\mathbf{B}$ ) with dominating on the face of the superficial branches of mandibular nerve: 1. External nasal branch of anterior ethmoidal nerve; 2 . Infratrochlear nerve; 3. Supratrochlear nerve; 4. Frontal nerve; 5 . Supraorbital nerve; 6. Zygomaticotemporal nerve; 7. Palpebral branches of lacrimal nerve; 8. Zygomaticofacial nerve; 9. Infraorbital nerve; 10. Mental nerve; 11. Long buccal nerve; 1. Auriculotemporal nerve; 13. Great auricular nerve; 14. Transverse cervical nerve

In the first type, the innervation of the face is dominated by the superficial branches of the maxillary nerve; its branches, zygomaticofacial and infraorbital nerves, are involved in sensitive innervation of the cheek area. The second type on the face is dominated by superficial sensory branches of the mandibular nerve; its branches, buccal and mental nerves, are involved in sensitive innervation of the cheek area [3]. At this time, buccal nerve forms a plexus with the facial nerve, infraorbital nerve, and mental nerve [4-7]. The individual variability of innervation of soft tissues of the maxillofacial area should be taken into account during local anesthesia.

In order to anesthetize the upper part of the cheek and soft tissues of the zygomatic area, besides the anesthesia of the buccal nerve, we performed a blockade of the zygomaticofacial nerve according to a technique, in which the anesthetic is injected at the lower outer edge of the orbit [8-10] where the zygomaticofacial foramina is located and where the branches of the zygomaticofacial nerve go outside the zygomatic bone [11] However, the buccal and zygomatic areas were completely anesthetized in $74 \%$ of cases. In $26 \%$ of cases with uncomplete anesthesia of buccal and zygomatic areas, we noticed that only the central part of the zygomatic region as well as the small area adjoining to the lower outer edge of the orbit were anesthetized. The upper part of the zygomatic region adjoining to the zygomaticofrontal suture and the lateral part adjoining to the zygomaticotemporal suture remained sensitive. In our opinion, the absence of the necessary anesthetic effect in these cases was associated with the individual anatomical variability of the branching of the zygomaticofacial nerve on the face. These patients were broadfaced or long-faced.

\section{OBJECTIVES}

The purpose of the study was to develop a method of conductive anesthesia of the zygomaticofacial nerve considering its individual topographic and anatomical features, and to evaluate its effectiveness in clinical conditions.

\section{MATERIAL AND METHODS}

Craniometric studies were performed on 32 natural skulls of corpses of various ages and 60 images of patients' head section were completed in a $3 \mathrm{D}$ reconstruction by multi-detector row spiral computed tomography (Aqualon, Toshiba Medical Systems, Japan). The cranial index represents the correlation between the transverse diameter (width) of the face and the longitudinal (length) in percentage. If the index is more than $80.9 \%$, 
the form of the skull should be attributed to brachycephalic (short-headed); if it is within $76.0-80.9 \%$, it is recognized as the mesocephalic (medium-headed). The shape of the skull, in which this figure was $75.9 \%$ or less, belonged to the dolichocephalic (long head). The number of fork-face foramina on each skull was calculated and features of their location were taken into account. The position of these openings was measured in relation to the fixed anatomical landmarks: zygomaticofrontal suture, zygomaticotemporal suture, lower outer edge of the orbit, and the proposed anatomical landmark for the injection on the side (facial) surface of the zygomatic bone.

Thirty surgical dental patients with planned surgical interventions on the lateral facial area (in the buccal area, 19 patients; in the zygomatic area, 11 patients) that have provided a written consent participated in the clinical observation. To all patients, a developed method of conducting anesthesia of the zygomaticofacial nerve was applied, and its effectiveness with a known method was compared [8-10] in 31 patients exposed to surgical interventions in the cheek area (17 cases) and zygomatic area (14 cases).

In order to detect individual anatomical features of the facial part of patients' heads, the facial index was determined by the Garson's formula as the relation between the morphological height of the face and its width multiplied by 100. Numeric value of facial index 79.0-83.9 defines the broad face (euryprosopne), 84.0-87.9 - middling face (mesoprosopne), 88.0-92.9 and more - oblong face (leptoprosopne) $[12,13]$. In the majority, euryprosopnic face shape describes the brachycephalic skull, mesoprosopnic face shape - mesocephalic skull, and leptoprosopnic face shape - dolichocephalic skull [3].

The zygomatic area was divided into four quadrants: the upper-front, upper-back, lower-front, and lower-back by imaginary, mutually perpendicular lines passed through its center. The buccal area was also divided into quadrants in a similar manner. Tactile sensitivity was investigated using nylon monofilaments. Pain sensitivity was determined by injection of a needle into the epidermis (pin prick sensation). The assessment of tactile and pain sensitivity was performed on a four-point scale in each quadrant: 0 points - no sensitivity, 1 point - sharply reduced sensitivity, 2 points - moderately reduced sensitivity, 3 points - completely preserved tactile and pain sensitivity. In case of pathological processes (benign tumors, keloid scars, or fistulas of migrating granulomas) located in the buccal region, surgical interventions were conducted under local anesthesia of buccal and zygomaticofacial nerves. Anesthesia of the buccal nerve was performed through the skin according to Yegorov's method [14], with anesthetic injected in the anterior edge of the base of coronary process of the mandible, where the buccal nerve passes.

The study was performed according to the principles of the Declaration of Helsinki, and was approved by the Ethics Committee of the Danylo Halytsky Lviv National Medical University.

The probability of obtained results was evaluated according to the Student's probability criterion by statistically computing the data using common methods of statistics from the Statistica-7 package, and statistical analysis was assessed using Pearson's $\chi^{2}$ test.

\section{RESULTS}

Anatomical variability of the structure of the skull was found as well as the variability of the amount of zygomaticofacial foramina. The dolichocephalic skull was determined in 34 cases, mesochephalic type in 40 cases, and brachycephalic type was found in 18 cases (Table 1 ).

There was a certain feature of the localization of $\mathrm{zy}$ gomaticofacial foramina on the lateral (facial) surface of zygomatic bone, depending on the type of structure of the skull. In people with mesocephalic skulls, foramina in most cases were located by "chain" corresponding to the lower-outer edge of the orbit, away from this anatomical formation at $8.2 \pm 2.3 \mathrm{~mm}$ (Figure 2).

In dolichocephalic skulls, zygomaticofacial foramina were grouped not only in the area adjacent to the lower-outer edge of the orbit. In $35.2 \%$ of cases, they were located at different distances between each other and were close to the zygomaticofrontal suture at $6.9 \pm 2.3 \mathrm{~mm}$ (Figure 3). In the brachycephalic skulls, most of the zygomaticofacial foramina were centered near the lowerouter edge of the orbit. They were located at a distance of $9.3 \pm 2.7 \mathrm{~mm}$ to zygomaticofrontal suture. However, in $33.3 \%$ of cases, they were shifted from the orbit to the zygomaticotemporal suture and were situated at a distance of $14.2 \pm 2.3 \mathrm{~mm}$ (Figure 4 ).

TABLE 1. Anatomical variability of the number of zygomaticofacial foramina depending on the types of skull structure

\begin{tabular}{|c|c|c|c|c|}
\hline \multirow{2}{*}{$\begin{array}{l}\text { Type of skull structure } \\
\text { (total number of cases) }\end{array}$} & \multicolumn{4}{|c|}{ Detected number of zygomaticofacial foramen on the analyzed skulls, number of studied skulls, $n$ (\%*) } \\
\hline & 1 foramen & 2 foramina & 3 foramina & 4 foramina \\
\hline Dolichocephalic type (34) & $10(29.4)$ & $12(35.3)$ & $9(26.4)$ & $3(8.8)$ \\
\hline Mesochephalic type (40) & $23(57.5)$ & $11(27.5)$ & $4(10.0)$ & $2(5.0)$ \\
\hline Brachycephalic type (18) & $7(38.9)$ & $6(33.3)$ & $5(27.8)$ & Not detected \\
\hline
\end{tabular}

* The percentage of cases in each group was counted according to the total number of skulls with the same type of structure 


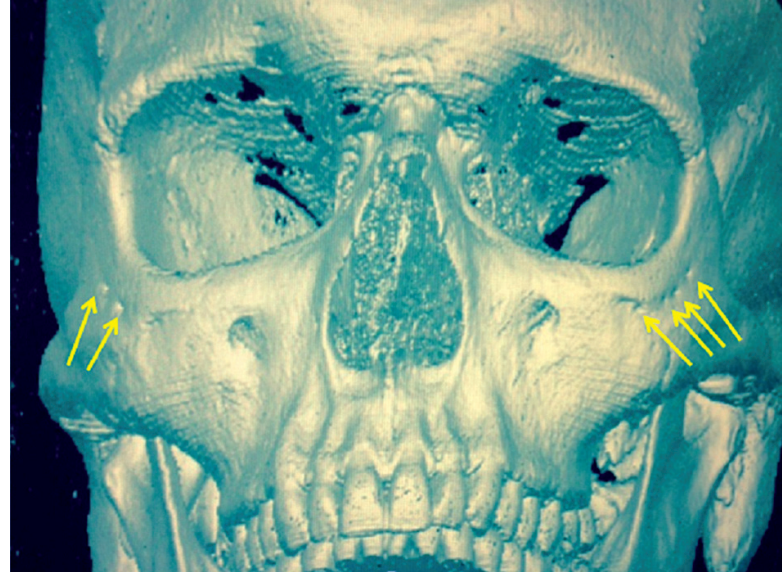

FIGURE 2. Computed tomography of the facial skull in 3D reconstruction. Craniometric study. Mesocephalic structure of the skull. There are four zygomaticofacial foramina on the facial surface of the zygomatic bone on the left and two zygomaticofacial foramina on the right (shown with arrows)

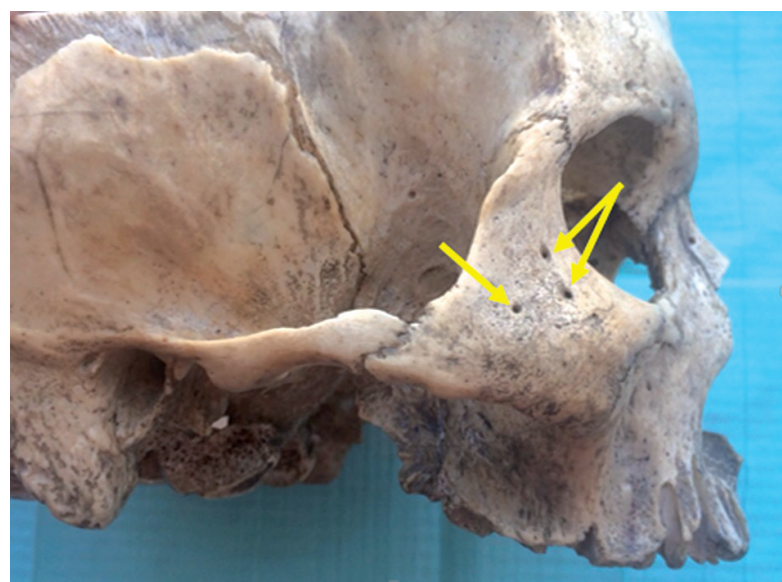

FIGURE 4. Craniometric study. Brachycephalic structure of the skull. Most of the zygomaticofacial foramina are centered near the lower-outer edge of the orbit. One of the zygomaticofacial foramina was shifted from the orbit to the zygomaticotemporal suture (shown with arrows)

Taking into account the results of craniometric studies as well as the individual topographic and anatomical features of zygomaticofacial nerve branching in people with different types of skull structure, we developed a technique of conducting anesthesia of the branches of zygomaticofacial nerve. The facial surface of the zygomatic bone resembles a scalene quadrangle, which differs in form in every person, depending on the type of structure of the skull. Therefore, anatomical landmark for anesthetic injection is determined individually in each patient. It is located at the intersection of two imaginary lines, which connects the opposite corners of quadrangle: a vertical, drawn from the zygomaticofrontal suture to the lower corner of zygomatic bone, and the horizon-

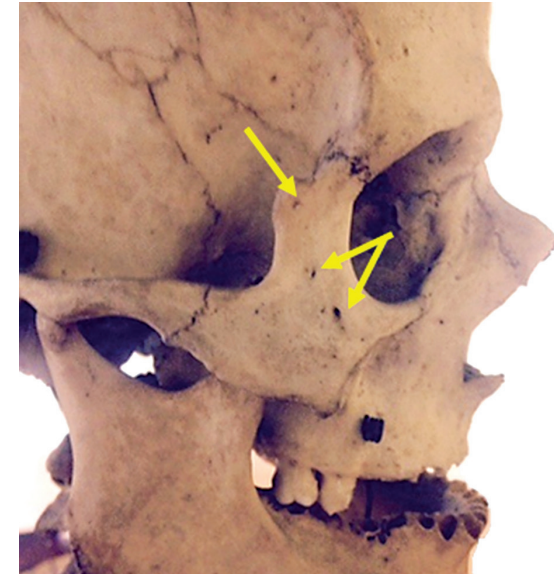

FIGURE 3. Craniometric study. Dolichocephalic structure of the skull. On the facial surface of the zygomatic bone there are three zygomaticofacial foramina, one of which is close to the zygomaticofrontal suture (shown with arrows)

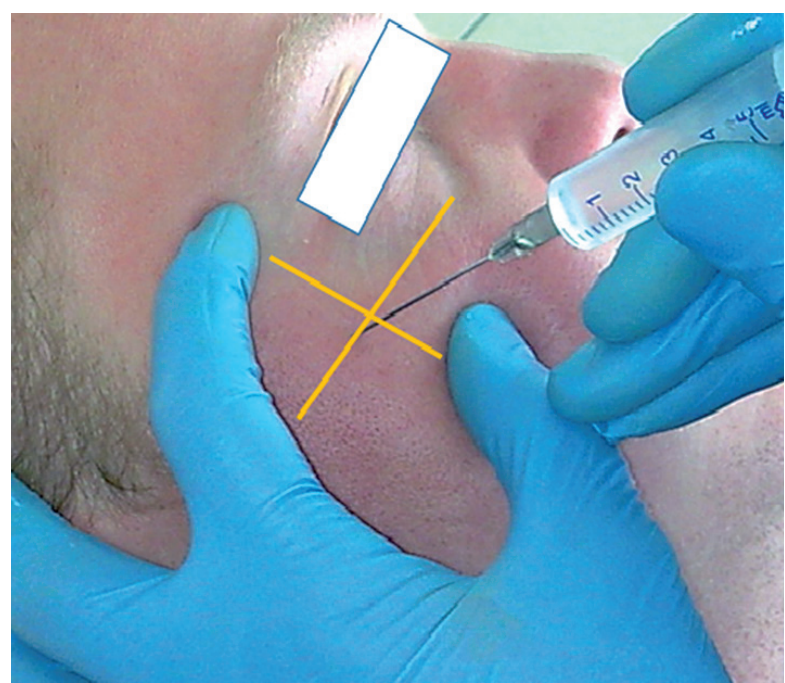

FIGURE 5. Blockade of the zygomaticofacial nerve (results of our research)

tal, drawn from the zygomaticotemporal suture to zygomaticomaxillary suture (Figure 5). Zygomaticofacial foramina are located within the imaginary ellipse, which the center is the place of the needle injection. The average distance to these openings along the large semi-axis is $10.4 \pm 4.8 \mathrm{~mm}$, and $5.7 \pm 1.5 \mathrm{~mm}$ along small one.

In people with mesoprosopnic face shape (mesocephalic skulls), a local anesthetic $(1.0 \mathrm{ml})$ is injected after the needle insertion into a definite anatomical landmark. In patients with leptoprosopnic face shape (dolichocephalic skulls), in order to exhaust all branches of the facial nerve, the needle after injection should be pushed forward by $1.0-1.5 \mathrm{~cm}$ vertically towards the frontal joint. In patients with euriprosopnic face shape (brachycephalic 
TABLE 2. The effectiveness of applied methods of anesthesia of zygomaticofacial nerve

\begin{tabular}{|l|l|l|c|}
$\begin{array}{l}\text { Groups of patients depending on applied method of anesthesia } \\
\text { of zygomaticofacial nerve }\end{array}$ & $\begin{array}{r}\text { The appearance of anesthesia of the soft tissues after } \\
\text { the blockade of zygomaticofacial nerve (number of cases) } \\
\text { Zygomatic area }\end{array}$ \\
\hline $\begin{array}{l}\text { Experimental group } \\
\text { (anesthesia of zygomaticofacial } \\
\text { nerve by the developed } \\
\text { method) }(n=20)\end{array}$ & Patients with euriprosopnic face shape $(n=5)$ & Anesthesia occurred in 3 cases & Anesthesia occurred in 2 cases \\
\cline { 2 - 5 } & Patients with mesoprosopnic face shape $(n=8)$ & Anesthesia occurred in 4 cases & Anesthesia occurred in 4 cases \\
\hline \multirow{2}{*}{$\begin{array}{l}\text { Control group (anesthesia } \\
\text { of zygomaticofacial nerve by } \\
\text { the known method) }(n=21)\end{array}$} & Patients with leptoprosopnic face shape $(n=7)$ & Anesthesia occurred in 4 cases & Anesthesia occurred in 3 cases \\
\cline { 2 - 5 } & Patients with mesoprosopnic face shape $(n=10)$ & Anesthesia occurred in 7 cases & Anesthesia occurred in 3 cases \\
\cline { 2 - 5 } & Path leptoprosopnic face shape $(n=6)$ & $\begin{array}{c}\text { Anesthesia occurred in } 2 \text { cases } \\
\text { Anesthesia did not occur in } 3 \text { cases }\end{array}$ & Anesthesia $0 c c u r r e d$ in 1 case \\
\hline
\end{tabular}

TABLE 3. Chi-square analysis when comparing to the applied methods of anesthesia of zygomaticofacial nerve

\begin{tabular}{|c|c|c|c|c|}
\hline $\begin{array}{l}\text { Comparable groups } \\
\text { ( } n_{1}-\text { experimental group; } n_{2}-\text { control group) }\end{array}$ & $\begin{array}{l}\text { Experimental group } \\
\text { The appearance } \\
\text { of anesthesia, } n(\%) \text { of cases }\end{array}$ & $\begin{array}{c}\text { Control group } \\
\text { The appearance } \\
\text { of anesthesia, } n(\%) \text { of cases }\end{array}$ & $\chi^{2}$ value & $p$ value \\
\hline Patients with euriprosopnic face shape $\left(n_{1}=5 ; n_{2}=5\right)$ & $5(100)$ & $0(0)$ & 10.0 & 0.002 \\
\hline Patients with leptoprosopic face shape $\left(\mathrm{n}_{1}=7 ; \mathrm{n}_{2}=6\right)$ & $7(100)$ & $3(50)$ & 4.55 & 0.03 \\
\hline Patients with mesoprosopic face shape $\left(n_{1}=8 ; n_{2}=10\right)$ & $8(100)$ & $10(100)$ & $\mathrm{NaN}$ & 1.000 \\
\hline Comparative assessment in general for groups $\left(n_{1}=20 ; n_{2}=21\right)$ & $20(100)$ & $13(61.9)$ & 9.46 & 0.003 \\
\hline
\end{tabular}

skulls), to block the branches of the zygomaticofacial nerve in the place where they reach the surface of the zygomatic bone, the needle should be directed horizontally 1.0-1.5 $\mathrm{cm}$ towards the zygomaticotemporal suture.

The effectiveness of the developed method of conducting anesthesia of zygomaticofacial nerve was studied in clinical conditions. After the blockade of the buccal nerve in 19 patients with various face shape before surgical interventions in the cheek area, it was found that in 10 patients (in $52.6 \%$ of cases), a complete buccal anesthesia did occur. In 9 patients (in $47.4 \%$ of cases), the cheek area was anesthetized only partially, with tactile and pain sensitivity remaining in the upper part of the cheek area: $1.5 \pm 0.5$ points $(p=0.008479)$. After an additional blockade of the branches of zygomaticofacial nerve, according to the developed technique, the above-mentioned topographic anatomical site was completely anesthetized in all patients regardless of the shape of the face, with tactile sensitivity 0.5 points and pain sensitivity 0 points. After the blockade of the zygomaticofacial nerve, in 11 patients with various face shape before surgical interventions in the zygomatic region, complete anesthesia in the zygomatic area was observed, with tactile and pain sensitivity resulted in 0 points (Table 2 ).

The loss of pain sensitivity of the skin in buccal and zygomatic regions confirmed the effectiveness of the developed method of conducting local anesthesia. During surgical treatment, the effectiveness of local anesthetic methods was evaluated as good; stable anesthesia with- out psychosomatic peculiarities, with no local and general complications was observed in patients.

In 14 patients of control group before surgical interventions in the zygomatic region after the anesthesia of zygomaticofacial nerve by known method, a complete anesthesia occurred in 7 patients with mesoprosopnic face shape and in 2 patients with leptoprosopnic face shape. In 5 patients, complete anesthesia was not achieved, with tactile and pain sensitivity remaining in the zygomatic region: $2.0 \pm 0.5$ points $(p=0.014956)$. Among them, 3 patients with leptoprosopnic face shape and 2 with euriprosopnic face shape were observed. In 17 patients of control group before surgical interventions in the cheek area after buccal nerve anesthesia by the standard method, complete anesthesia of the cheek area was achieved in 10 patients, while in 7 patients pain sensitivity remained in the upper part of this topographic anatomical region: $1.5 \pm 0.5$ points $(p=0.009552)$. After the additional zygomaticofacial nerve anesthesia by the known method, complete anesthesia of the cheek area was attained in 4 patients with mesoprosopnic and leptoprosopnic face shapes. In 3 patients with euriprosopnic face shape, pain perception remained in the upper part of the cheek (Table 2). The results of the $\mathrm{c}^{2}$ analysis are tabulated in Table 3.

This affirms that the introduction of local anesthetic to block the zygomaticofacial nerve by the known method near lower-outer edge of the orbit allows to achieve the needed effect only in patients with mesoprosopnic face 
shape. In order to anesthetize this nerve in people with broad and oblong face shape, anatomical variability of its branching should be considered.

\section{DISCUSSION}

The results of craniometric research of topographic anatomical peculiarities of zygomaticofacial foramina location on the facial surface of zygomatic bone turned out to be similar to the data of other authors regarding the variability of quantity and orderliness of zygomaticofacial foramina location [15-20]. There is great variability regarding the site of nerve division outside/inside the zygomatic bone and the number of foramina/canals, where nerves enter and leave the zygomatic bone [18]. The external surface of the zygomatic bone usually has one or two zygomaticofacial foramina. However, literary data varies regarding the frequency of cases with three zygomaticofacial foramina. The majority of researchers reports low level of such frequency, from $2.14 \%$ to $4.0 \%$ of cases $[17,19,20]$. Our results of the study are similar with the results of Hwang et al. [15] where three zygomaticofacial foramina in $9 \%$ of cases were found. The results of our craniometric study of orderliness of zygomaticofacial foramina location regarding constant anatomical landmarks such as zygomaticofrontal suture, zygomaticotemporal suture, and outer edge of the orbit are similar to the data of Mangesh (2016) and Ferro et al. (2017). According to those studies, zygomaticofacial foramina are usually located near lower-outer edge of the orbit [19], but occur in the so called "ZFF zone" (diameter of the zone, $25 \mathrm{~mm}$ ) at the different distance regarding the anatomical landmark that is the center of the facial surface of zygomatic bone [20]. However, these authors did not aim to find the connection between the topographic anatomical peculiarities of zygomaticofacial foramina location and the types of face shape that could have a practical value in choosing the anatomical landmarks during the blockade of zygomaticofacial nerve. The successful anesthesia of this nerve allows for painless intervention not only in zygomatic, but also in buccal area.

The main sensory nerve of the buccal region is the (long) buccal nerve $[21,22]$. The skin of the upper anterior part of the cheek is supplied by lateral rami of the large superior labial branch from the infraorbital nerve [23]. The lower part of the cheek is innervated by terminal branches from the superficial cervical plexus. The transverse cervical nerve (forming part of superficial cervical plexus) may contribute cutaneous sensory innervation to the skin of the inferior border of lateral and anterior mandible $[24,25]$. The clinical results of the research allow us to confirm that the upper part of the buccal area may be also innervated by zygomaticofacial nerve. This should be considered during surgical interventions on the soft tissues of lateral facial area.

\section{CONCLUSIONS}

For the successful local anesthesia of the buccal and zygomatic areas, it is necessary to take into account the anatomical variability of branching on the face of zygomaticofacial nerve in patients with different types of skull structure and face shape. Application in clinical conditions of the technique of conducting anesthesia of the zygomaticofacial nerve developed by us, in combination with the classical method of local anesthesia of the buccal nerve provides painless surgical interventions on the lateral area of the face.

\section{CONFLICT OF INTEREST}

The authors declare no potential conflicts of interest with respect to the research, authorship, and/ or publication of this article.

\section{References}

1. Siemionow M, Gharb BB, Rampazzo A. The face as a sensory organ. Plast Reconstr Surg 2011; 127: 652-662.

2. von Arx T, Abdelkarim AZ, Lozanoff S. The face - a neurosensory perspective. A literature review. Swiss Dental Journal SSO 2017; 127: 1066-1075.

3. Zolotareva TV, Toporov GN. Khirurgicheskaya anatomiya golovy [Surgical Head Anatomy]. Moskva: Meditsina; 1968, p. 224 [In Russian].

4. Alves N. Study of descendent course of buccal nerve in adults individuals. Int J Morphol 2009; 27: 295-298.

5. Wongsirichat N, Pairuchvej V, Arunakul S. Area extent anaesthesia from buccal nerve block. Int J Oral Maxillofac Surg 2011; 40: 601-604.

6. Yang HM, Won SY, Lee JG, et al. Sihler-stain study of buccal nerve distribution and its clinical implications. Oral Surg Oral Med Oral Pathol Oral Radiol 2012; 113: 334-339.

7. Takezawa K, Ghabriel M, Townsend G. The course and distribution of the buccal nerve: clinical relevance in dentistry. Australian Dental Journal 2018; 63: 66-71.

8. Niamtu J (ed.). Cosmetic Facial Surgery. St. Louis: Mosby; 2010, p. 784

9. Niteen DV. Local Anesthesia for Cosmetic Procedures, Clinical Use of Local Anesthetics. Rijeka: InTech; 2012, p. 102.

10. Gómez-Mayordomo V, Gutiérrez-Viedma Á, Porta-Etessam J, et al. Zygomaticofacial neuralgia: a new cause of facial pain. Headache 2018; 58: 455-457.

11. Senthil Kumar S, Kesavi D. Incidence and location of zygomaticofacial foramen in adult human skulls. Int J Med Res Health Sci 2014; 3: 80-83.

12. Naini FB. Facial aesthetics: concepts and clinical diagnosis. $1^{\text {th }}$ ed Oxford: Wiley-Blackwell; 2011, p. 456.

13. Trivedi H, Azam A, Tandon R, et al. Correlation between morphological facial index and canine relationship in adults - an anthropometric study. J Orofac Sci 2017; 9: 16-21.

14. Yegorov PM. Mestnoye obezbolevaniye v stomatologii [Local anesthesia in dentistry]. Moskva: Meditsina; 1985, p. 169 [In Russian].

15. Hwang SH, Jin S, Hwang K. Location of the zygomaticofacial foramen related to malar reduction. J Craniofac Surg 2007; 18: 872-874.

16. Aksu F, Ceri NG, Arman C, et al. Location and incidence of the zygomaticofacial foramen: an anatomic study. Clin Anat 2009; 22: 559-562.

17. Krishnamurthy A, Roshni S, Murlimanju BV, et al. Foramina on the zygomatic bone: its clinical significance. Clin Ter 2011; 162: 419-421. 
18. Kim HS, Oh JH, Choi DY, et al. Three-dimensional courses of zygomaticofacial and zygomaticotemporal canals using micro-computed tomography in Koreans. J Craniofac Surg 2013; 24: 15651568.

19. Lone M, Telang A, Rajgopal L, Bhuiyan PS. Location and incidence of the zygomatico-facial foramen in dry human skulls: an natomical study. Journal of the Anatomical Society of India 2016; 65: 164166.

20. Ferro A, Basyuni S, Brassett C, et al. Study of anatomical variations of the zygomaticofacial foramen and calculation of reliable reference points for operation. Br J Oral Maxillofac Surg 2017; 55: 1035-1041.

21. Wongsirichat N, Pairuchvej V, Arunakul S. Area extent anaesthesia from buccal nerve block. Int J Oral Maxillofac Surg 2011; 40: 601-604.

22. Yang HM, Won SY, Lee JG, et al. Sihler-stain study of buccal nerve distribution and its clinical implications. Oral Surg Oral Med Oral Pathol Oral Radiol 2012; 113: 334-339.

23. Joo W, Yoshioka F, Funaki T, et al. Microsurgical anatomy of the trigeminal nerve. Clin Anat 2014; 27: 61-88.

24. Lin K, Uzbelger Feldman D, Barbe MF. Transverse cervical nerve: implications for dental anesthesia. Clin Anat 2013; 26: 688-692.

25. Ella B, Langbour N, Caix P, et al. Transverse cervical and great auricular nerve distribution in the mandibular area: a study in human cadavers. Clin Anat 2015; 28: 109-117. 